STRUCTURAL BIOLOGY

ISSN 2059-7983

Received 17 May 2016

Accepted 27 July 2016

Edited by Z. S. Derewenda, University of Virginia, USA

₹ These authors share first authorship.

Keywords: interferon- $\gamma$ receptor 2 ; fibronectin type III domain; class 2 cytokine receptors.

PDB reference: interferon- $\gamma$ receptor $2,5 \mathrm{eh} 1$

Supporting information: this article has supporting information at journals.iucr.org/d

\section{Crystal structure of human interferon- $\gamma$ receptor 2 reveals the structural basis for receptor specificity}

\author{
Pavel Mikulecký,‡ Jirí Zahradník,‡ Petr Kolenko, Jiří Černý, Tatsiana Charnavets, \\ Lucie Kolářová, Iva Nečasová, Phuong Ngoc Pham and Bohdan Schneider*
}

Institute of Biotechnology CAS, BIOCEV, Prumyslova 595, 25250 Vestec, Czech Republic. *Correspondence e-mail: bohdan.schneider@gmail.com

Interferon- $\gamma$ receptor 2 is a cell-surface receptor that is required for interferon- $\gamma$ signalling and therefore plays a critical immunoregulatory role in innate and adaptive immunity against viral and also bacterial and protozoal infections. A crystal structure of the extracellular part of human interferon- $\gamma$ receptor 2 (IFN $\gamma$ R2) was solved by molecular replacement at $1.8 \AA$ resolution. Similar to other class 2 receptors, IFN $\gamma \mathrm{R} 2$ has two fibronectin type III domains. The characteristic structural features of IFN $\gamma \mathrm{R} 2$ are concentrated in its $\mathrm{N}$-terminal domain: an extensive $\pi$-cation motif of stacked residues KWRWRH, a NAGW-NAG sandwich (where NAG stands for $\mathrm{N}$-acetyl-D-glucosamine) and finally a helix formed by residues 78-85, which is unique among class 2 receptors. Mass spectrometry and mutational analyses showed the importance of $\mathrm{N}$-linked glycosylation to the stability of the protein and confirmed the presence of two disulfide bonds. Structure-based bioinformatic analysis revealed independent evolutionary behaviour of both receptor domains and, together with multiple sequence alignment, identified putative binding sites for interferon- $\gamma$ and receptor 1, the ligands of IFN $\gamma \mathrm{R} 2$.

\section{Introduction}

Interferon- $\gamma$ receptor 2 is a cell-surface receptor that represents a crucial molecule in the interferon- $\gamma$ (IFN $\gamma)$ signalization pathway, influencing innate and adaptive immunity against pathogens and tumours (Schoenborn \& Wilson, 2007; Lin \& Young, 2013). The signalling cascade is initiated by the binding of IFN $\gamma$ to its high-affinity cell surface receptor 1 , forming a binary complex with a structure that has already been determined [PDB entries 1fg9 (Thiel et al., 2000) and 1fyh (Landar et al., 2000)]. However, to activate this binary complex and activate the JAK/STAT signalization pathway (Jung et al., 1987; Cook et al., 1994; Hemmi et al., 1994), IFN $\gamma$ receptor 2 must participate in a ternary complex created by a homodimer of IFN $\gamma$, two molecules of receptor 1 and molecule(s) of receptor 2. To date, detailed structural and biophysical characterization of IFN $\gamma$ receptor 2, the key molecule for proper IFN $\gamma$ signalization, is lacking.

From its sequence similarity, IFN $\gamma$ receptor 2 (also known as IFN $\gamma$ receptor $\beta$ chain or accessory factor $1, \mathrm{AF}-1)$, has been classified as a member of the class 2 receptor family. This large group of cytokine receptors includes IFN $\gamma$ receptor 1 , receptors of interferon- $\alpha$ and interferon- $\beta$, receptors of interleukin-10 and interleukin-20, and receptors of other interleukins belonging to the IL-10 family (Langer et al., 2004). The mature IFN $\gamma$ receptor 2 protein comprises of 310 amino acids and has a predicted molecular mass of $35 \mathrm{kDa}$. It consists of a relatively short 69-amino-acid intracellular domain, a 21-amino-acid transmembrane domain and a 220 - 
amino-acid extracellular domain that is structured into two fibronectin type III domains. The extracellular domain contains five cysteine residues and six potential N-linked glycosylation sites. Such extensive glycosylation contributes to a significant size heterogeneity, which is observed even when the receptor molecule is isolated from the same cell type; the molecular weight of mature receptor 2 of human interferon- $\gamma$ ranges from 61 to $67 \mathrm{kDa}$ (Bach et al., 1995).

Despite its biological significance, three-dimensional structural data on IFN $\gamma$ receptor 2 are lacking. Here, we report a $1.8 \AA$ resolution crystal structure of the extracellular portion of IFN $\gamma$ receptor 2 (hereafter called IFN $\gamma$ R2); the structure has been deposited in the Protein Data Bank as entry 5eh1. The structure and sequence of IFN $\gamma \mathrm{R} 2$ are discussed in the context of the structures and sequences of the related class 2 cytokine receptors, with emphasis on the sequentially closest receptors of interleukins from the IL-10 family. Structurebased and sequence-based alignments suggested regions securing binding specificity of these receptors for their cytokine ligands.

\section{Materials and methods}

\subsection{Cloning, expression and purification of IFN $\gamma \mathbb{R} 2$}

The gene encoding the extracellular part of IFN $\gamma \mathrm{R} 2$ (residues 28-247 of UniProt entry P38484) was cloned into a Drosophila pMT-BiP-V5-His_A vector using BglII and AgeI restriction enzymes in frame with an $\mathrm{N}$-terminal $\mathrm{BiP}$ signal peptide and a $\mathrm{C}$-terminal $6 \times \mathrm{His}$ tag. This expression vector was co-transfected into insect Schneider S2 cells along with the pCoBlast selection plasmid using Effectene Transfection Reagent according to the manufacturer's instructions. Blasticidin-resistant $\mathrm{S} 2$ cells were selected by growing the cells in HyClone SFX Medium supplemented with $10 \%$ FBS and $25 \mu \mathrm{g} \mathrm{ml}^{-1}$ blasticidin S. Large-scale protein expression was achieved after expansion and substitution into HyClone SFX serum-free medium, and protein expression was induced by the addition of $0.75 \mathrm{mM} \mathrm{CuSO}_{4}$ for $6 \mathrm{~d}$ (the cell concentration was approximately 35 million per millilitre) and $1.5 \mathrm{mM}$ $\mathrm{CuSO}_{4}$ for a further $2 \mathrm{~d}$ until the percentage of living cells did not decrease below $95 \%$. After expression, the cells were discarded by centrifugation and the medium containing secreted glycosylated IFN $\gamma \mathrm{R} 2$ protein was supplemented with the following additives at the following final concentrations: $5 \mathrm{~m} M \mathrm{CaCl}_{2}, 1 \mathrm{~m} M \mathrm{NiSO}_{4}, 250 \mathrm{~m} M \mathrm{NaCl}$ and $50 \mathrm{~m} M$ Tris$\mathrm{HCl} \mathrm{pH}$ 8. The protein was purified on an IMAC HP column charged with $\mathrm{NiSO}_{4}$ and equilibrated with EQ buffer ( $50 \mathrm{mM}$ Tris- $\mathrm{HCl} \mathrm{pH} 8,500 \mathrm{mM} \mathrm{NaCl}$ ). The column was washed with W buffer $(50 \mathrm{~m} M$ Tris- $\mathrm{HCl} \mathrm{pH} 8,500 \mathrm{mM} \mathrm{NaCl}, 20 \mathrm{~m} M$ imidazole $\mathrm{pH} 8$ ) and the protein was eluted with EL buffer (50 m $M$ Tris- $\mathrm{HCl} \mathrm{pH} \mathrm{8,} 500 \mathrm{~m} M \mathrm{NaCl}, 250 \mathrm{~m} M$ imidazole $\mathrm{pH}$ $8)$. It was further purified to homogeneity by size-exclusion chromatography at room temperature on a HiLoad 16/600 Superdex 200 pg column (GE Healthcare) equilibrated with HN buffer (10 $\mathrm{m} M$ HEPES pH 7.5, $100 \mathrm{mM} \mathrm{NaCl})$. Samples were analyzed by $12 \%$ SDS-PAGE.
IFN $\gamma \mathrm{R} 2$ was produced in insect cells as a secreted protein bearing oligosaccharide moieties of approximately $10 \mathrm{kDa}$ according to SDS-PAGE analysis. Deglycosylation by peptide: $\mathrm{N}$-glycosidase F (PNGase F) or endoglycosidase H (Endo H) with a C-terminal Strep-tag ( $\$$ S1, Supporting Information) was performed after purification of IFN $\gamma \mathrm{R} 2$ on an IMAC column during dialysis against $\mathrm{TN}$ buffer $(50 \mathrm{~m} M$ Tris buffer $\mathrm{pH} 8$, $150 \mathrm{mM} \mathrm{NaCl}$ ) or $\mathrm{HN}$ buffer, respectively. Endoglycosidases were removed on a Strep-Tactin column and the nonbound fraction containing IFN $\gamma \mathrm{R} 2$ was further purified by sizeexclusion chromatography in $\mathrm{HN}$ buffer.

The single IFN $\gamma$ R2 variants (N110Q, N137Q and N231Q, respectively) were introduced using the QuikChange II SiteDirected Mutagenesis Kit (Agilent Technologies). Primers are listed in Supplementary Table S1. The fully mutated IFN $\gamma$ R2 variant bearing N56Q, N110Q, N137Q and N231Q mutations was obtained as a GeneArt Strings DNA Fragment and was cloned with the same protocol as the wild type. The expression and purification of all IFN $\gamma \mathrm{R} 2$ variants were performed in the same way as described above.

\subsection{Biophysical measurements}

Circular-dichroism (CD) spectra were recorded using a Chirascan-plus spectrometer (Applied Photophysics) in steps of $1 \mathrm{~nm}$ over the wavelength range 185-260 nm. Samples diluted with water to a concentration of $0.2 \mathrm{mg} \mathrm{ml}^{-1}$ were placed into the holder in a $0.05 \mathrm{~cm}$ path-length quartz cell and individual spectra were recorded at a temperature of $23^{\circ} \mathrm{C}$. The CD signal was expressed as the ellipticity and the resulting spectra were buffer-subtracted. To analyze the ratio of secondary structures, we used the CDNN program (Böhm et al., 1992) provided with the Chirascan CD spectrometer. CD melting measurements were performed using samples diluted with water to a protein concentration of $0.5 \mathrm{mg} \mathrm{ml}^{-1}$. A $10 \mathrm{~mm}$ path-length quartz cell was placed into the thermostated holder and sample absorption was recorded at $280 \mathrm{~nm}$ in $1^{\circ} \mathrm{C}$ increments at a rate of $0.5^{\circ} \mathrm{C} \mathrm{min}^{-1}$ over the temperature range $20-85^{\circ} \mathrm{C}$ with an averaging time of $12 \mathrm{~s}$. Melting curves were normalized to relative values between 0.0 and 1.0 to visually magnify differences between the melting profiles, and the melting temperature $\left(T_{\mathrm{m}}\right)$ was estimated from the first derivative of the melting curves.

\subsection{Glycosylation analysis and disulfide-bond determination}

IFN $\gamma$ R2 glycosylation sites were determined by MALDIMS analysis preceded by protein digestion as described previously (Plíhal et al., 2004). Disulfide bonds in IFN $\gamma$ R2 were determined by SDS-PAGE and subsequent identification by mass spectrometry (MS) in analogy to the previously described procedure (Pompach et al., 2009). $20 \mu \mathrm{g}$ of sample in nonreducing conditions was loaded onto a $4-12 \%$ gradient gel (Life Technologies) in the presence of $200 \mu M$ cystamine. Bands corresponding to highly glycosylated IFN $\gamma \mathrm{R} 2$ were excised and subjected to in-gel deglycosylation and proteolysis. Deglycosylation using Endo $\mathrm{H}$ (New England Biolabs) was carried out for $4 \mathrm{~h}$ at $37^{\circ} \mathrm{C}$ and the resulting 
Table 1

Data-collection statistics and structure-refinement parameters.

Values in parentheses are for the highest resolution shell.

\begin{tabular}{ll}
\hline X-ray source & MX 14.1, HZB \\
Wavelength $(\AA)$ & 0.91841 \\
Total oscillation angle $\left({ }^{\circ}\right)$ & 180 \\
Resolution range $(\AA)$ & $62.88-1.80(1.91-1.80)$ \\
Space group & $P 66_{1} 22$ \\
Unit-cell parameters $(\AA)$ & $a=b=58.102, c=377.266$ \\
No. of measured reflections & $688675(110540)$ \\
No. of unique reflections & $36723(5733)$ \\
Average multiplicity & $18.8(19.3)$ \\
Completeness $(\%)$ & $99.9(99.8)$ \\
Average $I / \sigma(I)$ & $17.6(2.5)$ \\
Overall $B$ factor from Wilson plot $\left(\AA^{2}\right)$ & 20 \\
Average $B$ factor $\left(\AA^{2}\right)$ & 28 \\
No. of non-H atoms & \\
$\quad$ Protein & 1734 \\
Saccharides & 42 \\
Waters & 311 \\
All & 2121 \\
$R_{\text {merge }}$ & $0.148(1.395)$ \\
Half-data-set correlation coefficient $\mathrm{CC}_{1 / 2}$ & $99.9(81.2)$ \\
No. of reflections, test set & 1820 \\
Final $R_{\text {work }} / R_{\text {free }} / R_{\text {all }}$ & $0.190 / 0.222 / 0.191$ \\
Ramachandran plot & \\
$\quad$ Residues in favoured region & $213[96.3 \%]$ \\
Residues in allowed regions & $219[99.1 \%]$ \\
Outliers & $2[0.9 \%]$ \\
\hline
\end{tabular}

partly deglycosylated sample was digested with trypsin (sequencing grade, Promega) for $12 \mathrm{~h}$ at $37^{\circ} \mathrm{C}$ at a protein:enzyme ratio of $30: 1(w / w)$. After digestion, the tryptic peptide mixture was desalted on a peptide MicroTrap column (Michrom Bioresources) and separated on a reversed-phase C18 column (Acclaim PepMap 100, $5 \mu \mathrm{m}, 0.1 \times 20 \mathrm{~mm}$; Thermo Scientific). The mobile phases consisted of $0.1 \%$ formic acid in $2 \%$ acetonitrile (solvent $A$ ) and $0.1 \%$ formic acid in $98 \%$ acetonitrile (solvent $B$ ). Peptides were eluted under the following gradient conditions: $2-45 \%$ solvent $B$ in $40 \mathrm{~min}, 45-95 \%$ solvent $B$ in $5 \mathrm{~min}$. The flow rate was $0.5 \mu \mathrm{min}^{-1}$ and the column was directly connected to the mass spectrometer. Mass spectra were acquired on a solariX XR FTMS instrument equipped with a $12 \mathrm{~T}$ superconducting magnet (Bruker Daltonics). For the identification of disulfide bonds, we used the Links algorithm, previously described as ASAP (Automated Spectrum Assignment Program; Schilling et $a l ., 2003)$. To generate deconvoluted spectra and export the $m /$ $z$ values, we used a script utilizing the $S N A P 2.0$ algorithm of the DataAnalysis 4.2 software suite (Bruker Daltonics).

\subsection{Crystallization and diffraction data collection}

Crystals of Endo H-deglycosylated IFN $\gamma \mathrm{R} 2$ receptor were grown using the sitting-drop vapour-diffusion method in 96-3 three-well Intelli-Plate trays (Art Robbins Instruments). The reservoir solution consisted of $0.1 M \mathrm{MES}$ pH 5.0, $10 \%$ PEG 6000 (final pH 6.0): condition No. 61 of The JCSG Core I Suite (Qiagen). Drops consisting of $0.2 \mu \mathrm{l}$ protein sample (15 $\mathrm{mg} \mathrm{ml}^{-1}$ protein in $\mathrm{HN}$ buffer) and $0.2 \mu \mathrm{l}$ reservoir solution were prepared with a Gryphon liquid-pipette robot (Dunn Labortechnik) and were equilibrated against $100 \mu \mathrm{l}$ reservoir solution. Crystals appeared after $30 \mathrm{~d}$ of incubation at $291 \mathrm{~K}$. Crystals were mounted in Round LithoLoops (Molecular Dimensions) and flash-cooled in liquid nitrogen after cryoprotection in $20 \%(v / v)$ glycerol. X-ray diffraction data were collected at $100 \mathrm{~K}$ on beamline MX 14.1 of the BESSY II synchrotron-radiation source at the HelmholtzZentrum Berlin (HZB). A native data set was collected at a wavelength of $0.918 \AA$.

\subsection{Data processing, structure determination and refinement}

The diffraction and refinement statistics are summarized in Table 1. Diffraction data were processed and scaled using the $X D S$ program package (Kabsch, 2010). The structure was solved with BALBES (Long et al., 2008), but the structure model needed significant manual remodelling. Only the C-terminal domain of IFN $\gamma \mathrm{R} 2$ was found and the initial $R$ factors were about 0.49 and 0.52 for $R_{\text {work }}$ and $R_{\text {free, }}$, respectively. Residues missing from the initial model were built in with significant help from $A R P / w A R P$ (Langer et al., 2008); manual corrections and building were performed using Coot (Emsley \& Cowtan, 2004). Refinement was then carried out with REFMAC5 (Murshudov et al., 2011) and the structure was validated by MolProbity (Chen et al., 2010). The coordinates and structure factors have been deposited in the PDB with accession code $5 \mathrm{eh} 1$.

\subsection{Sequence and structural bioinformatics}

The UniProt database was searched with the BLAST tool (Camacho et al., 2009) using the sequence of the extracellular part of IFN $\gamma \mathrm{R} 2$ as the query sequence. The automated result was manually reviewed to select 90 sequences from different species. These sequences were used to calculate a multiple sequence alignment with Clustal Omega (Sievers et al., 2011) as implemented in UGENE (Okonechnikov et al., 2012). The ConSurf server (Glaser et al., 2003) was used to estimate the evolutionary conservation of amino-acid positions in the protein structures. The calculations were based on the crystal structure of IFN $\gamma \mathrm{R} 2$ (PDB entry 5eh1) and the alignment prepared by Clustal Omega. Structural comparison was prepared by MatchMaker as implemented in the UCSF Chimera software (Pettersen et al., 2004).

Root-mean-square deviation (r.m.s.d.) values between the $\mathrm{N}$ - and C-terminal domains were calculated using $V M D$ (Humphrey et al., 1996). The backbone atoms of 34 sequentially conserved residues in each domain (listed in Supplementary Table S2) were used for the structure superposition of all possible pairs of $\mathrm{N}$ - and $\mathrm{C}$-terminal domains of the 12 available crystal structures of class 2 cytokine receptors. The $V M D$ commands measure fit and move were used for the structural overlay, followed by measure rmsd operating on the same selection of residues and backbone atoms for the calculation of r.m.s.d. values. The stability of the N-terminal domain of IFN $\gamma \mathrm{R} 2$ was estimated by calculating the pairwise interaction energy at the DFT-D level as detailed in Supplementary Fig. S3. 


\section{Results and discussion}

\subsection{Summary}

IFN $\gamma$ R2 was produced in insect S2 cells, purified, characterized by biophysical techniques (Fig. 1) and its crystal structure was solved at $1.8 \AA$ resolution. Fig. 2 highlights some of the structural features of IFN $\gamma$ R2; Figs. 3 and 4 provide a comparison of IFN $\gamma \mathrm{R} 2$ to the other cytokine receptors from the class 2 family, with the aim of correlating the sequences and structures of these proteins.

\subsection{Glycosylation and overall fold stability}

The IFN $\gamma$ R2 protein has six potential glycosylation sites (Asn56, Asn110, Asn137, Asn231, Asn85 and Asn219), of which the first four were confirmed by mass-spectrometric analysis as glycosylated in our construct; the crystal structure later revealed that position Asn85 was also glycosylated. The greatest heterogeneity was observed at position Asn137. To remove oligosaccharide moieties from these residues, we used two endoglycosidases, Endo $\mathrm{H}$ and PNGase F, but both enzymes left several forms of IFN $\gamma \mathrm{R} 2$ with residual glycosylation as observed by a distribution of molecular mass on SDS-PAGE (Supplementary Fig. S1). Mass spectrometry identified $\alpha(1-3)$-fucose at position Asn231. Because $\alpha(1-3)$ fucose abolishes the activity of both endoglycosidases, its presence is a likely to be reason for the mass distribution of IFN $\gamma$ R2. Deglycosylation by Endo $H$ caused an approximately $7 \mathrm{kDa}$ shift in molecular weight on SDS-PAGE and, in contrast to deglycosylation by PNGase, did not induce protein oligomerization, as checked by size-exclusion chromatography. Measurements using CD spectroscopy (Fig. 1) and thermal shift assay ( $\$ \mathrm{~S} 1$ in Supporting Information and Supplementary Fig. S2) showed no significant difference in melting temperatures between the glycosylated and Endo $\mathrm{H}$ deglycosylated forms of the IFN $\gamma \mathrm{R} 2$ protein. Because the CD spectra of these two forms are also virtually identical, we

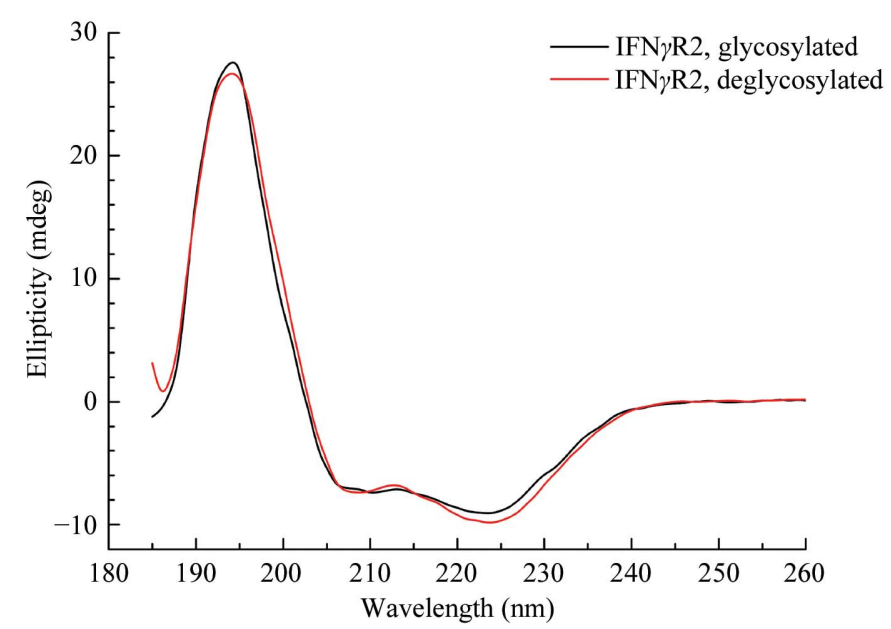

believe that deglycosylation does not influence the secondary structure of IFN $\gamma$ R2. Although the CD spectra of IFN $\gamma \mathrm{R} 2$ and IFN $\gamma$ R1 differ considerably (Černý et al., 2015), both proteins belong to the same fold of the fibronectin type III domain family (Pfam PF00041).

Besides deglycosylation by the endoglycosidases, we designated asparagine-to-glutamine mutants to decrease the level of glycosylation. We prepared a fully mutated IFN $\gamma \mathrm{R} 2$ variant bearing N56Q, N110Q, N137Q and N231Q mutations and single-point mutants N110Q, N137Q and N231Q, respectively. All of these constructs were transfected into insect S2 cells, but none of them were secreted into the cellculture medium. This correlates with the earlier observation that IFN $\gamma$ R2 mutants with changed glycosylation patterns were located in the cytoplasmic fraction (Moncada-Vélez, 2013). Structurally significant is glycosylation at positions Asn110 and Asn137, where the bound $N$-acetyl-D-glucosamine (NAG) residues sandwich Trp131 (Fig. 2b), thus shielding its hydrophobic surfaces from solvent. As suggested by the failure to express and/or purify the N56Q, N110Q, $\mathrm{N} 137 \mathrm{Q}$ and $\mathrm{N} 231 \mathrm{Q}$ mutants, glycosylation is necessary for IFN $\gamma$ R 2 production by stabilizing the fold and transport to and/or across the cellular membrane.

\subsection{The IFN $\gamma R 2$ fold is stable without disulfide bonds}

IFN $\gamma$ R2 contains five cysteine residues, and our massspectrometric analysis identified disulfide bonds linking Cys86 to Cys94 and Cys209 to Cys234. We observed the same protein mobility under nonreducing and reducing conditions during SDS-PAGE analysis. The melting temperature of both glycosylated and deglycosylated IFN $\gamma \mathrm{R} 2$ measured by thermal shift assay (Supplementary Fig. S2) decreased by only $\sim 1^{\circ} \mathrm{C}$ in the presence of $5 \mathrm{~m} M$ TCEP (a reducing agent to break the disulfide bonds), so that the IFN $\gamma \mathrm{R} 2$ fold is stable without $\mathrm{S}-\mathrm{S}$ bonds. This contrasts with the behaviour of IFN $\gamma$ R1 (Fountoulakis et al., 1990), in which the protein fold is

Figure 1

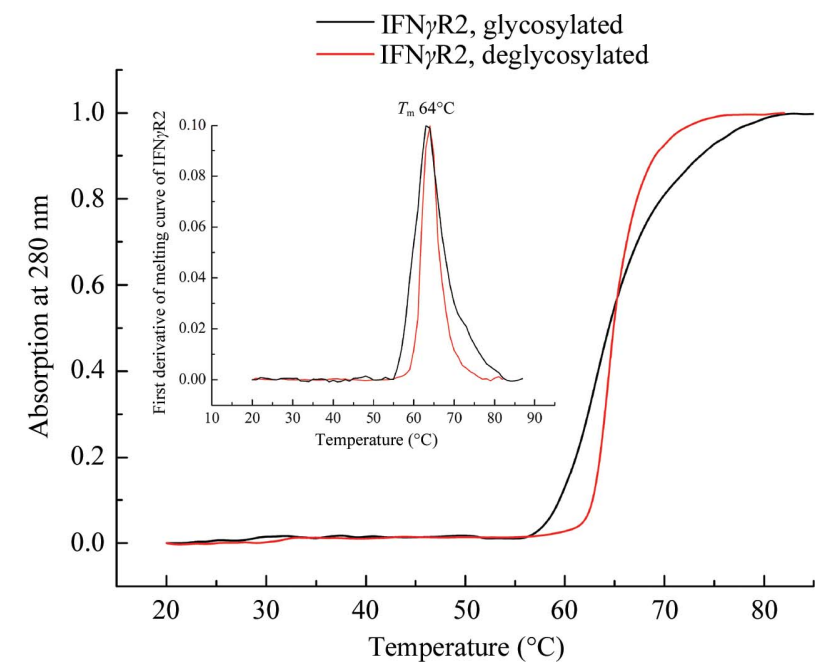

Left: circular-dichroism (CD) spectra of glycosylated and deglycosylated IFN $\gamma$ R2. The CD spectra of both proteins are highly similar, suggesting that the partial removal of the oligosaccharide moieties did not affect the overall structure of IFN $\gamma \mathrm{R} 2$. Right: normalized melting curves measured from temperature-dependent $\mathrm{CD}$ spectra at $280 \mathrm{~nm}$. The melting temperature was estimated as $64^{\circ} \mathrm{C}$ for both glycosylated and deglycosylated IFN $\gamma \mathrm{R} 2$. 
stabilized to a large extent by $\mathrm{S}-\mathrm{S}$ bridges. The fifth IFN $\gamma \mathrm{R} 2$ cysteine residue, Cys174, does not form an intramolecular $\mathrm{S}-\mathrm{S}$ bridge but is bound to a monomeric cysteine. Binding of free cysteine to the sterically accessible Cys 174 probably occurs after secreting IFN $\gamma$ R2 into the cell-culture medium, which contains free cysteine and stabilizes the monomeric form of IFN $\gamma$ R2.

\subsection{The overall structure of the extracellular portion of IFN $\gamma \mathrm{R} 2$}

The structure of IFN $\gamma \mathrm{R} 2$ was solved at $1.8 \AA$ resolution and electron density was observed for amino-acid residues $28-240$ of UniProt entry P38484, except for two two-residue loops. Data-collection and refinement parameters are shown in Table 1. The extracellular part of the IFN $\gamma \mathrm{R} 2$ molecule consists of two domains (Fig. 2), the N-terminal D1 domain of UniProt residues 28-133 and the C-terminal D2 domain of residues 144-247. Both domains belong to the immuno- globulin fold with fibronectin type III topology, forming $\beta$-sandwiches (Pfam PF00041). The inter-domain torsion angle is approximately $120^{\circ}$, similar to those of IFN $\gamma \mathrm{R} 1$ (Thiel et al., 2000; Walter et al., 1995) and human tissue factor (Harlos et al., 1994); the D1-D2 torsion angle is defined in Supplementary Table S3. The D1 domain is composed of three $\beta$-strands stacked on a layer of four $\beta$-strands, and the $\mathrm{D} 2$ domain is created by four $\beta$-strands arranged against four other $\beta$-strands; both domains are connected by a short linker (residues 134-143 in IFN $\gamma$ R2) comprising a short helix that is also found in IFN $\gamma$ R1, human tissue factor and other receptors.

\subsection{Structural motifs in D1 and D2}

D1 contains a distinct structural motif of six stacked residues: Lys68, Trp74, Arg114, Trp126, Arg116 and His123. The average distance between the mean planes of the individual side chains of this extensive $\pi$-cation interaction is $3.65 \AA$.
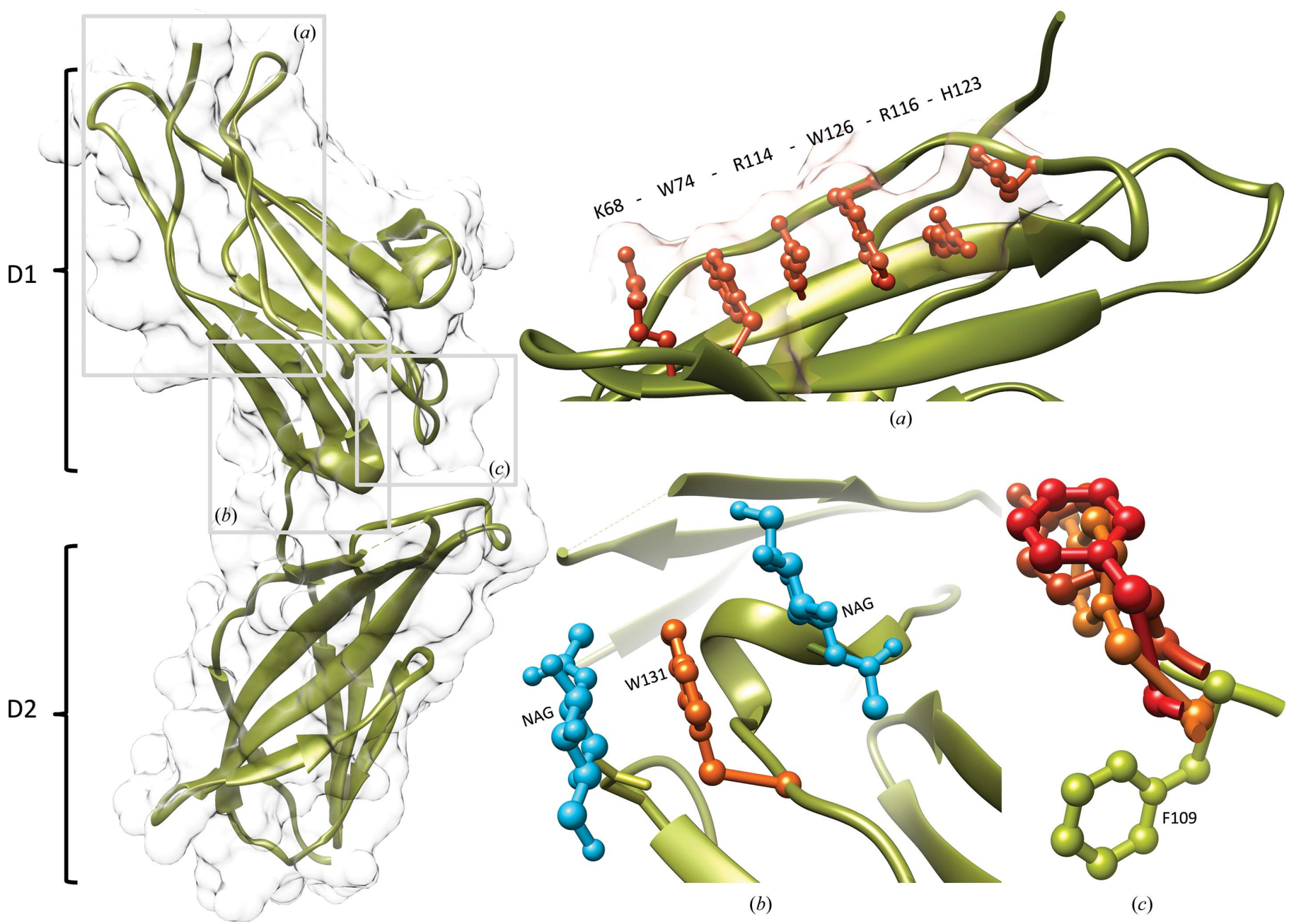

(a)

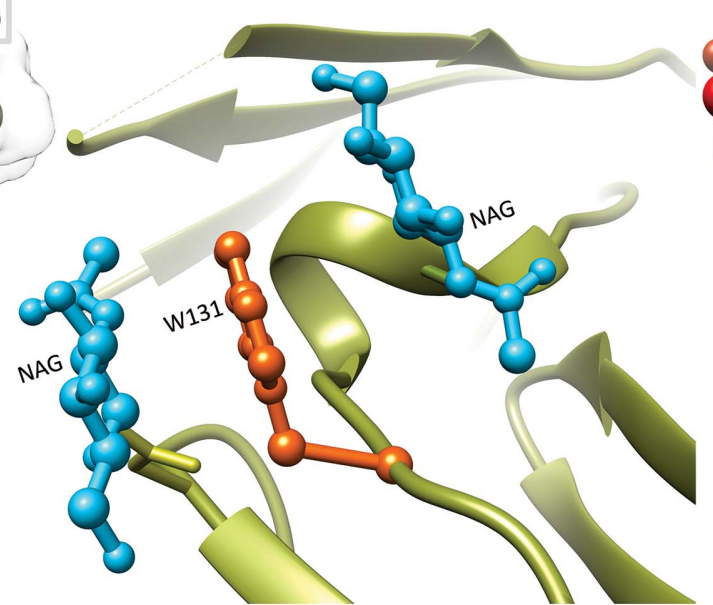

(b)

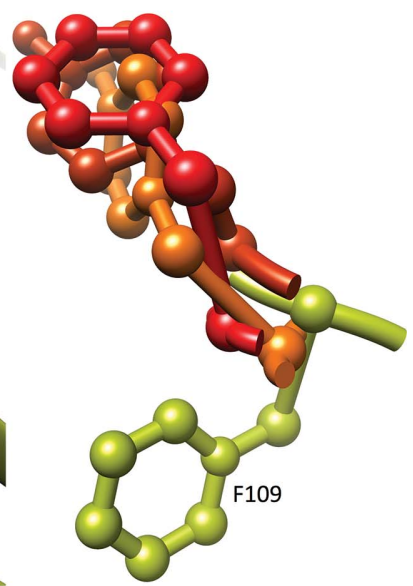

(c)

Figure 2

Left: ribbon and surface representations of the IFN $\gamma$ R2 structure. D1 and D2 indicate domains 1 and 2, respectively. Insets: (a) residues Lys68, Trp74, Arg114, Trp126, Arg116 and His123 of the D1 domain form a stacking motif on the IFN $\gamma$ R2 surface. (b) N-Acetyl-D-glucosamines (NAGs; blue) glycosylating Asn110 and Asn137 sandwich Trp131 (orange), reducing its hydrophobic character. (c) The superposition of aromatic binding epitopes shows differences between IFN $\gamma$ R2 (Phe109 in green) on one side and promiscuous shared cytokine receptors on the other [in red; Tyr82 of IL10R2 (PDB entry 3lqm; Yoon et al., 2010), Phe169 of gp130 (PDB entry 1bqu; Bravo et al., 1998) and Tyr103 of $\gamma_{\mathrm{c}}$ receptor (PDB entry 4gs7; Ring et al., 2012)]. No corresponding aromatic residue is observed in IL20R2 (Logsdon et al., 2012). 
Analysis of the interaction energies in D1 revealed that the motif contributes significantly to the overall stability of the whole domain. These six surface residues are involved in interactions that are comparable in strength to the hydrophobic core of the domain and are likely to play an important role in the process of domain folding. The residues responsible for domain stability are depicted in Supplementary Fig. S3, in which the colour and thickness of the cartoon representation show the relative interaction energy per residue ranging from low (blue) to high (red) stabilizing values.

An analogous stacking motif with the consensus sequence WSXWS (Bazan, 1990) has been predicted by sequence alignments in D1 of the class 1 receptor family (McElroy et al., 2009), but such a motif is missing in the D2 domains of both class 1 and class 2 receptors. Based on the presence of the KWRWRH motif in IFN $\gamma$ R2, we performed structural alignment of the class 2 receptor structures and discovered a similar but sequentially noncontinuous motif with the sequence $(X)$ WRWR $(X)$, where $X$ is $\mathrm{K}, \mathrm{R}$ or $\mathrm{H}$. The important role of large aromatic tryptophan residues in stabilizing the fibronectin fold by stitching together two $\beta$-strands is accompanied in D1 by a structural role for charged residues, especially arginines. Besides the discussed $(X)$ WRWR $(X)$ motif, we found a tight overlap of a continuous chain of residues R-L/V-R-A (residues Arg114-Leu115-Arg116-Ala117 in IFN $\gamma$ R2): the average r.m.s.d. between motifs from two receptors is $0.6 \AA$. The other important residues that are conserved in D1 of the available class 2 receptor structures are residues corresponding to Trp49, Ser124 and the Cys86/Cys96 pair forming a disulfide bond in IFN $\gamma \mathrm{R} 2$. A unique feature of IFN $\gamma$ R2 D1 is a short helix (residues 78-85), which is present in no other discussed receptor structure.

Sequential and structural comparison of D2 revealed a considerable sequence variability, within which we identified the conservation of two proline residues, Pro142 and Pro143, and the structurally well conserved motif 175-YNVAXW-180, with r.m.s.d. values about $1 \AA$ but low sequence similarity. Another characteristic structural feature of D2 is the formation of a disulfide bridge between Cys209 and Cys234. Higher values for the $B$ factors in D2 indicate its higher flexibility compared with D1. A higher flexibility of D2 compared with D1 was also indicated in our previous studies of IFN $\gamma \mathrm{R} 1$ (Mikulecký et al., 2013; Černý et al., 2015).

\subsection{Structural alignment of domains $D 1$ and $D 2$ in IF $\gamma \gamma R 2$ and in other class 2 receptors}

We performed alignment of the IFN $\gamma \mathrm{R} 2$ structure with the 11 remaining available structures of the class 2 receptor family in order to gauge their similarity and reveal their unique features. The alignment was measured by overlapping 34 residues in the $\mathrm{N}$-terminal $\mathrm{D} 1$ and the same number of residues in the C-terminal D2; the r.m.s.d. values of the overlapped residues are listed in Fig. 3 and the overlapped residues are listed in Supplementary Table S2. The D1 domains are mutually more similar than the D2 domains, as highlighted by

\begin{tabular}{c|cccccccccccc|c|} 
PDB code & Ifg9 & 5eh1 & 1j7v & 3lqm & 4doh & 4doh & 3dlq & 3g9v & 3og6 & 3se4 & 3se4 & 2puq \\
Chain ID & $C$ & $A$ & $R$ & $A$ & $E$ & $B$ & $R$ & $A$ & $B$ & $A$ & $C$ & $T$ \\
Receptor & IFNpR1 & IFNyR2 & IL10R1 & IL10R2 & IL20R1 & IL20R2 & IL22R & IL22BP & IL28R & IFNaR1 & IFNaR2 & TF \\
\hline IFNyR1 & 0.82 & 0.87 & 0.73 & 0.73 & 0.80 & 0.78 & 0.90 & 0.71 & 0.82 & 1.35 & 1.12 & 0.85 \\
IFNyR2 & 1.27 & 0.79 & 0.93 & 0.97 & 0.79 & 0.79 & 0.96 & 0.80 & 0.85 & 1.45 & 1.25 & 1.04 \\
IL10R1 & 1.22 & 1.12 & 1.07 & 0.74 & 0.97 & 0.88 & 0.94 & 1.43 & 1.13 & 0.81 & 0.67 & 0.66 \\
IL10R2 & 1.00 & 1.14 & 1.05 & 0.89 & 0.95 & 1.05 & 0.65 & 0.87 & 0.68 & 0.80 & 1.11 & 0.93 \\
IL20R1 & 0.93 & 1.32 & 0.89 & 1.33 & 1.59 & 0.93 & 0.97 & 0.63 & 0.75 & 0.59 & 1.36 & 1.15 \\
IL20R2 & 1.32 & 1.51 & 1.23 & 0.99 & 1.33 & 0.91 & 0.93 & 0.66 & 0.82 & 1.48 & 1.25 & 1.21 \\
IL22R & 1.20 & 1.49 & 1.09 & 0.86 & 1.04 & 1.16 & 4.19 & 1.20 & 1.19 & 0.87 & 0.98 & 1.03 \\
IL22BP & 1.32 & 1.48 & 0.94 & 1.20 & 1.18 & 1.30 & 1.17 & 0.93 & 1.02 & 1.16 & 1.11 & 0.96 \\
IL28R & 1.21 & 1.16 & 1.34 & 1.29 & 1.30 & 1.32 & 1.18 & 1.45 & 0.91 & 1.09 & 0.77 & 0.86 \\
IFNaR1 & 1.16 & 0.96 & 1.31 & 1.33 & 1.33 & 0.98 & 1.75 & 1.26 & 1.59 & 1.77 & 0.94 & 1.20 \\
IFNaR2 & 1.35 & 1.80 & 1.40 & 1.29 & 1.19 & 1.81 & 1.58 & 1.14 & 1.46 & 1.22 & 1.43 & 1.02 \\
TF & 1.38 & 1.16 & 1.23 & 1.26 & 1.44 & 1.04 & 1.16 & 1.40 & 1.43 & 1.16 & 1.81 & 0.86 \\
\hline
\end{tabular}

Figure 3

Structural differences between the N-terminal (D1) and C-terminal (D2) domains of 12 class 2 cytokine receptors gauged by the r.m.s.d. values for backbone atoms of their 34 residues. R.m.s.d. values comparing D1 and D2 domains are shown above and below the diagonal, respectively. For instance, comparison between D1 of IL20R2 and IL22BP gives an r.m.s.d. of $0.66 \AA$; the r.m.s.d. between their D2 domains is $1.30 \AA$ A. R.m.s.d. values that are smaller and larger than the off-diagonal average r.m.s.d. value are highlighted in blue and red hues, respectively. The diagonal (in grey) shows the lowest r.m.s.d. values for 34 residues from D1 and D2 within each receptor structure; the r.m.s.d. between D1 and D2 of IL10R2 is $0.89 \AA$ A. References to the analyzed structures are as follows: IFN $\gamma$ R1, Thiel et al. (2000); IFN $\gamma$ R2, this work; IL10R1, Josephson et al. (2001); IL10R2, Yoon et al. (2010); IL20R1 and IL20R2, Logsdon et al. (2012); IL22R, Bleicher et al. (2008); IL22BP, de Moura et al. (2009); IL28R, Miknis et al. (2010); IFN $\alpha$ R1 and IFN $\alpha$ R2, Thomas et al. (2011); TF (human tissue factor), Larsen et al. (2007). 
blue and red hues in Fig. 3; the average r.m.s.d. between two D1 domains is $0.95 \AA$ and that between two D2 domains is $1.3 \AA$. A high similarity within D1 and D2, respectively, indicates that modulation of the specificity of receptors takes place in only a few variable regions, which are discussed below.

D1 domains bear two conflicting structural features: strict fold conservation reflected by high structural similarity of the selected residues, and at the same time the presence of two structurally highly variable loops corresponding to residues $70-73$ and $97-107$ in IFN $\gamma$ R2. The third variable loop was located in the D2 domain (residues $162-171$ in IFN $\gamma \mathrm{R} 2$ ); the loops are coloured red and yellow for D1 and green for D2 in Fig. 4. Given the fairly uniform core of both domains and variability concentrated in the three localized regions, we suggest that the binding specificity of the individual receptors is controlled by these variable regions. However, there is another factor that contributes to the receptor specificity, the different mutual orientation of D1 and D2 (Supplementary Table S3), which displaces these variable regions to different positions, thus providing a unique binding interface for each receptor.

Several structural and sequential features of receptors of interferon- $\alpha$ and interferon- $\beta$ (PDB entry 3se4; Thomas et al., 2011), here labelled IFN $\alpha$ R1 and IFN $\alpha$ R2, distinguishes them from the other analyzed receptors. Specifically, IFN $\alpha$ R 1 is composed of four instead of two domains; here, we analyzed D1 and D2. The D3-D4 pair cannot be analyzed as D4 is not resolved in the electron density. Further dissimilarities of IFN $\alpha \mathrm{R} 1$ and IFN $\alpha \mathrm{R} 2$ are found in the composition of their $\pi-$ cation motifs: in IFN $\alpha$ R1 only four residues stack in D1 (Trp46, Arg76, Trp87 and Arg78) and three in D3 (Trp250, Arg279 and Trp291), while D1 of IFN $\alpha$ R2 does not have the motif at all and is replaced by the motif YVTV.

\subsection{Similarity among receptors and consequences for evolution}

As discovered previously (Yoon et al., 2010), an aromatic tyrosine or phenylalanine residue situated in the cleft between D1 and D2 of gp130 (PDB entry 1bqu; Bravo et al., 1998), $\gamma_{\mathrm{c}}$ (PDB entry 4gs7; Ring et al., 2012) and IL10R2 (PDB entry 3lqm; Yoon et al., 2010) serves as the key binding epitope of promiscuous class 1 and 2 receptors, implying the existence of a common ancestor. Superposition of these receptor structures shows that the orientation of Phe109 and three residues in gp130, $\gamma_{c}$ and IL10R2 are quite different (Fig. 2c). No preferred rotamer of Phe109 overlaps the three former residues without significant rebuilding of the IFN $\gamma \mathrm{R} 2$ backbone. The structural difference between IFN $\gamma \mathrm{R} 2$ and the other receptors, especially IL10R2, is significant and suggests that there is not a common binding epitope for these receptors.

Significant sequence similarity between IFN $\gamma$ R2, IL10R2 and IL20R2 (20-25\% sequence identity among different species; analysis not shown) points to their evolutionary relationship. If proven, it would be analogous to the evolutionary relationship between receptors 1 of the cytokines IFN $\gamma$ R1, IL10R1 and IL20R1 (Langer et al., 2004). We may therefore hypothesize that these three cytokine systems have evolved from a common ancestral system: while interferon- $\gamma$ evolved early in evolution and is known in fish species (Savan et al., 2009), its receptor 2 emerged later in connection with the evolution of amphibians. The specific function of IFN $\gamma$ R2 therefore evolved from an older promiscuously functioning molecule. A likely candidate is IL10R2, because it is evolutionarily older and is known in primitive fishes, while IL20R2 emerges similarly to IFN $\gamma \mathrm{R} 2$ in amphibians. The lack of a common binding epitope between IFN $\gamma \mathrm{R} 2$ and the other class 2 receptors, notably IL10R2 (Fig. 2c), indirectly supports this hypothesis.

3.8. The sequence alignment of IFN $\gamma \mathrm{R} 2$ from various species suggests its binding interface

In an attempt to identify the putative interface by which IFN $\gamma \mathrm{R} 2$ forms a functional ternary complex with its binding partners interferon- $\gamma$ and receptor 1 , we aligned the IFN $\gamma$ R2 sequences from 90 species and used the ConSurf server to project the consensus onto the structure of IFN $\gamma$ R2 (Fig. $4 b$ ). The 32 conserved residues (purple in Fig. 4b) are mainly located in the inward arched part of the U-shaped receptor molecule. This part of the molecule contains the previously described stacking motif (Fig. 2a) and plays an important role in maintaining the overall structure. The 34 most variable residues are predominantly on the opposite side of the molecule (cyan in Fig. 4b). These regions of sequentially least conserved residues coincide with the location of the structurally variable loops derived by the superposition of receptor structures. We therefore conclude that the putative IFN $\gamma \mathrm{R} 2$ interface for forming the active ternary complex with IFN $\gamma$ and IFN $\gamma \mathrm{R} 1$ is likely to be in the receptor 2 region with the most variable residues. This conclusion is supported by an analogous observation in the IFN $\gamma \mathrm{R} 1$ system: the least sequentially conserved residues form the interface with the binding partner (Mikulecký et al., 2013).

The composition of the ternary signalling complexes of dimeric cytokines discussed here, IFN $\gamma$ and IL-10, is understood less than for monomeric examples such as IL-20, for which the ternary complex has a known crystal structure (Logsdon et al., 2012). One of the reasons is the existence of two binding interfaces in the dimeric cytokines and the resulting different and more complex stoichiometry of the complexes; the crystal structure of an IFN $\gamma$-IFN $\gamma$ R1 complex with an unexpected 2:3 stoichiometry serves as an example (Thiel et al., 2000). The topology and structure of the signalling ternary complex of IFN $\gamma$ have been extensively studied and reviewed (Pestka et al., 1997; Hoffmann et al., 2015). Experiments in solution and on the cell surfaces indicated a 2:2:2 or 2:2:1 stoichiometry of the signalling IFN $\gamma$ complex (Marsters et al., 1995); cross-linking of different components of the IFN $\gamma$ complex expressed in cloned cell lines have shown direct contact between IFN $\gamma \mathrm{R} 1$ and IFN $\gamma \mathrm{R} 2$ (Krause et al., 2006) and also between IFN $\gamma$ and IFN $\gamma$ R2 (Kotenko et al., 1995). The newly determined structure of IFN $\gamma \mathrm{R} 2$ may spur new experiments exploring the topology and three-dimensional structure of the signalizing ternary complex of IFN $\gamma$. 


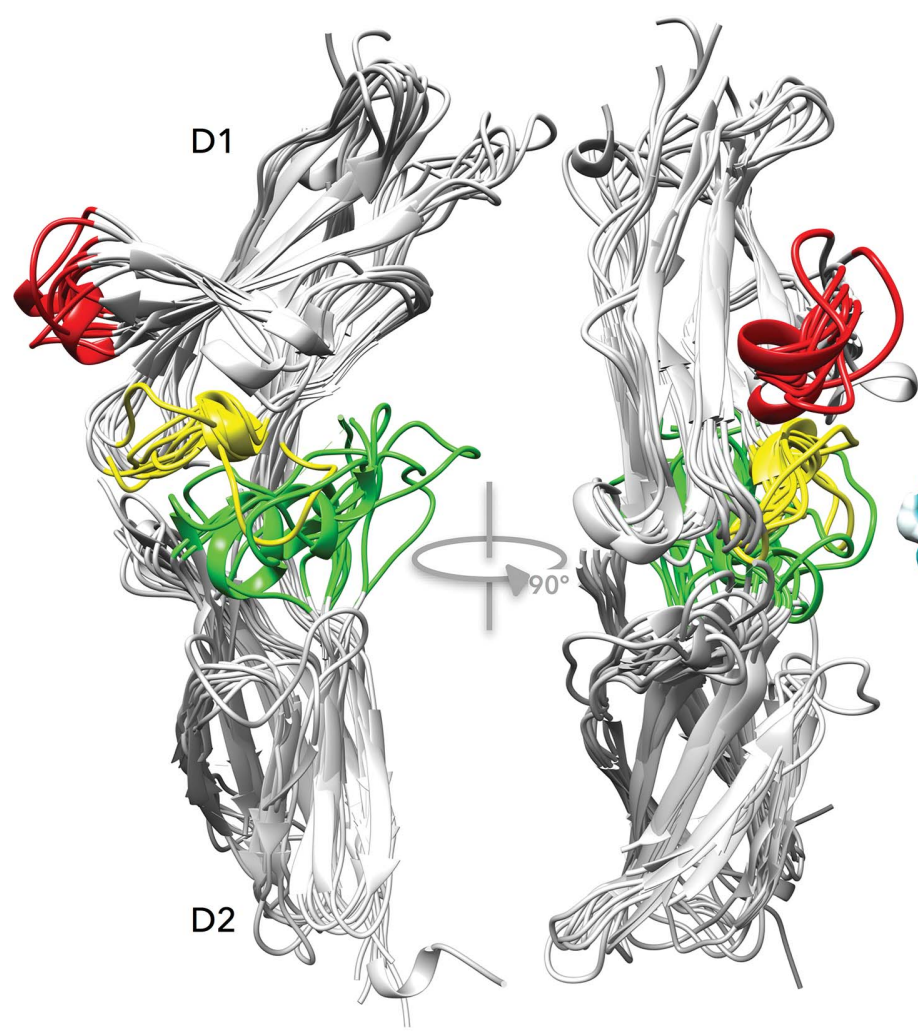

(a)

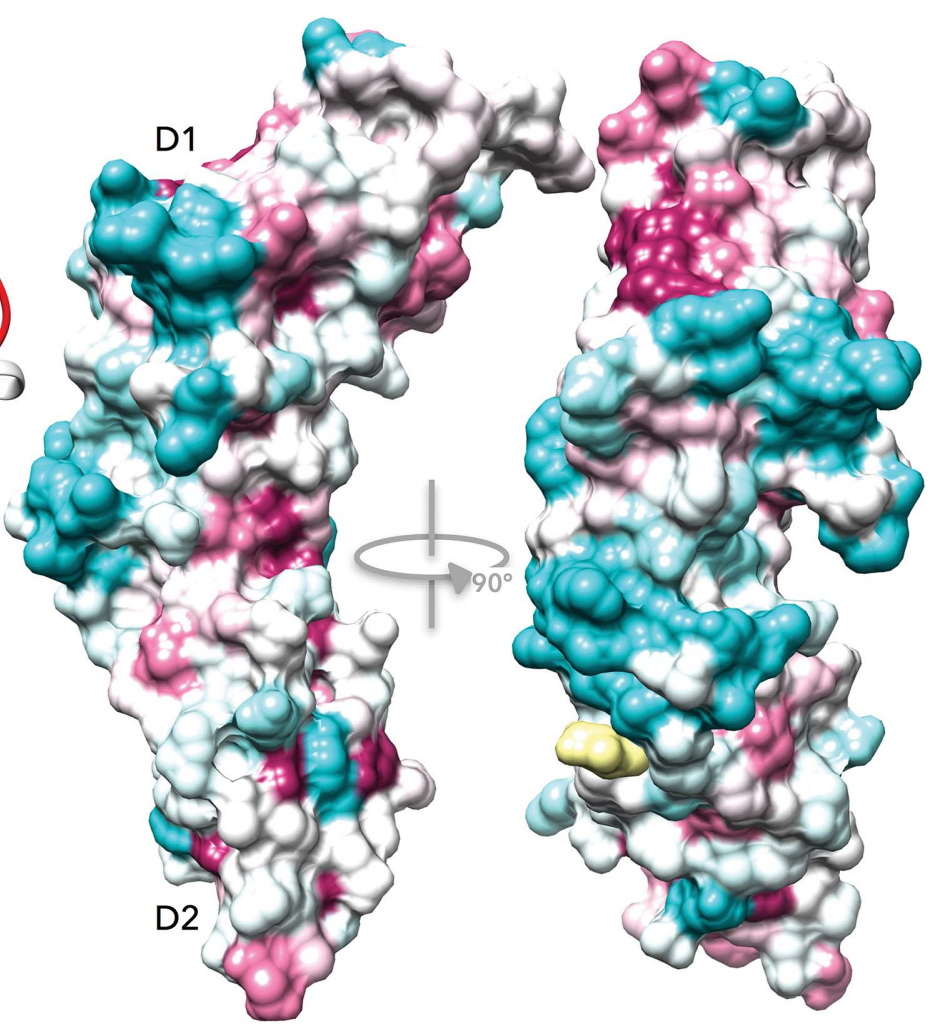

(b)

Figure 4

Structurally variable regions and a proposed interaction interface of the cytokine receptors. (a) Cartoon representation of the structural superposition of the D1 and D2 domains of the nine receptor structures. The backbone of the selected residues (listed in Supplementary Table S2) was superimposed independently for each domain and was then drawn on top of the IFN $\gamma$ R2 structure. The aligned cores of both domains overlap tightly (for r.m.s.d. values, see Fig. 3), but two regions in D1 (red and yellow) and one in D2 (green) are highly variable. (b) Sequences of IFN $\gamma$ R2 from 90 species with the sequentially most variable regions coloured cyan and conserved regions in purple drawn on the surface of the IFN $\gamma \mathrm{R} 2$ structure by ConSurf (Glaser $e t$ al., 2003). The IFN $\gamma \mathrm{R} 2$ free cysteine Cys174 is highlighted in yellow. (a) and (b) show IFN $\gamma \mathrm{R} 2$ in the same orientation.

\section{Conclusions}

A partially deglycosylated extracellular part of the interferon$\gamma$ receptor 2 , IFN $\gamma \mathrm{R} 2$, was crystallized and its structure was determined at $1.8 \AA$ resolution and deposited in the PDB with accession code $5 \mathrm{eh} 1$. The electron-density map was interpreted for amino-acid residues 28-240, apart from two short loops. The IFN $\gamma \mathrm{R} 2$ structure revealed the fold common to other cytokine receptors: two fibronectin type III domains connected by a short linker. IFN $\gamma \mathrm{R} 2$ is a glycoprotein with five of the six potential $\mathrm{N}$-linked glycosylation sites glycosylated, as confirmed by mass spectrometry and the crystal structure. Our analysis of glycosylation also uncovers the role of the oligosaccharide moieties at Asn110 and Asn137, which sandwich Trp131 and shield its hydrophobic aromatic ring from the solvent. Both potential disulfide bonds form but are not critical for the stability of IFN $\gamma \mathrm{R} 2$, as it is also stable in a reducing environment. The fifth cysteine Cys174 is bound to the monomeric cysteine.

Structure and sequence alignments revealed some important features of the 12 class 2 receptors. Their N-terminal D1 domains are more mutually similar than their C-terminal D2 domains (Fig. 3). D1 carries a distinctive so far unrecognized structural feature: a $\pi$-cation motif of sequentially distant stacked residues $(X) \mathrm{WRWR}(X) \quad(\mathrm{KWRWRH}$ in $\operatorname{IFN} \gamma \mathrm{R} 2$;
Fig. 2a). Analysis of the receptor structures revealed three structurally highly variable regions (Fig. $4 a$ ), which most likely bring about binding specificity for their interacting partners. This hypothesis is further supported by the alignment of IFN $\gamma$ R2 sequences from various species, which identified the highest sequence variability at positions coinciding with the structurally variable regions (Fig. 4b). An important structural feature distinguishing IFN $\gamma \mathrm{R} 2$ from the related IL10R2, gp130 and $\gamma_{\mathrm{c}}$ receptors is the specific positioning of the aromatic recognition epitope in IFN $\gamma \mathrm{R} 2$ (Fig. $2 c$ ).

We believe that the determination of the structure of the sofar missing component of the interferon- $\gamma$ signalling complex will enable a deeper understanding of the functioning of this important immunity cascade.

\section{Related literature}

The following references are cited in the Supporting Information for this article: Cancino-Díaz et al. (2002), Černý et al. (2007), Furche et al. (2014), O'Boyle et al. (2011) and Rüger et al. (2015).

\section{Acknowledgements}

This study was supported by the Czech Science Foundation (GA CR) grant No. 16-20507S and by project BIOCEV 
CZ.1.05/1.1.00/02.0109 from the ERDF. It was conducted at the Institute of Biotechnology CAS with help of the institutional grant RVO: 86652036. We thank HZB for the allocation of synchrotron-radiation beamtime.

\section{References}

Bach, E. A., Szabo, S. J., Dighe, A. S., Ashkenazi, A., Aguet, M., Murphy, K. M. \& Schreiber, R. D. (1995). Science, 270, 1215-1218. Bazan, J. F. (1990). Proc. Natl Acad. Sci. USA, 87, 6934-6938.

Bleicher, L., de Moura, P. R., Watanabe, L., Colau, D., Dumoutier, L., Renauld, J.-C. \& Polikarpov, I. (2008). FEBS Lett. 582, 2985-2992.

Böhm, G., Muhr, R. \& Jaenicke, R. (1992). Protein Eng. Des. Sel. 5, 191-195.

Bravo, J., Staunton, D., Heath, J. K. \& Jones, E. Y. (1998). EMBO J. 17, 1665-1674.

Camacho, C., Coulouris, G., Avagyan, V., Ma, N., Papadopoulos, J., Bealer, K. \& Madden, T. L. (2009). BMC Bioinformatics, 10, 421.

Cancino-Díaz, J. C., Reyes-Maldonado, E., Bañuelos-Pánuco, C. A., Jiménez-Zamudio, L., García-Latorre, E., León-Dorantes, G., Blancas-González, F., Paredes-Cabrera, G. \& Cancino-Díaz, M. E. (2002). J. Investig. Dermatol. 119, 1114-1120.

Černý, J., Biedermannová, L., Mikulecký, P., Zahradnik, J., Charnavets, T., Šebo, P. \& Schneider, B. (2015). Biomed Res. Int. 2015, 716945.

Černý, J., Jurečka, P., Hobza, P. \& Valdés, H. (2007). J. Phys. Chem. A, 111, 1146-1154.

Chen, V. B., Arendall, W. B., Headd, J. J., Keedy, D. A., Immormino, R. M., Kapral, G. J., Murray, L. W., Richardson, J. S. \& Richardson, D. C. (2010). Acta Cryst. D66, 12-21.

Cook, J. R., Emanuel, S. L., Donnelly, R. J., Soh, J., Mariano, T. M., Schwartz, B., Rhee, S. \& Pestka, S. (1994). J. Biol. Chem. 269, 70137018.

Emsley, P. \& Cowtan, K. (2004). Acta Cryst. D60, 2126-2132.

Fountoulakis, M., Juranville, J.-F., Stüber, D., Weibel, E. K. \& Garotta, G. (1990). J. Biol. Chem. 265, 13268-13275.

Furche, F., Ahlrichs, R., Hättig, C., Klopper, W., Sierka, M. \& Weigend, F. (2014). Wiley Interdiscipl. Rev. Comput. Mol. Sci. 4, 91-100.

Glaser, F., Pupko, T., Paz, I., Bell, R. E., Bechor-Shental, D., Martz, E. \& Ben-Tal, N. (2003). Bioinformatics, 19, 163-164.

Harlos, K., Martin, D. M., O’Brien, D. P., Jones, E. Y., Stuart, D. I., Polikarpov, I., Miller, A., Tuddenham, E. G. \& Boys, C. W. (1994). Nature (London), 370, 662-666.

Hemmi, S., Böhni, R., Stark, G., Di Marco, F. \& Aguet, M. (1994). Cell, 76, 803-810.

Hoffmann, H. H., Schneider, W. M. \& Rice, C. M. (2015). Trends Immunol. 36, 124-138.

Humphrey, W., Dalke, A. \& Schulten, K. (1996). J. Mol. Graph. 14, 33-38.

Josephson, K., Logsdon, N. J. \& Walter, M. R. (2001). Immunity, 15, 35-46.

Jung, V., Rashidbaigi, A., Jones, C., Tischfield, J. A., Shows, T. B. \& Pestka, S. (1987). Proc. Natl Acad. Sci. USA, 84, 4151-4155.

Kabsch, W. (2010). Acta Cryst. D66, 125-132.

Kotenko, S. V., Izotova, L. S., Pollack, B. P., Mariano, T. M., Donnelly, R. J., Muthukumaran, G., Cook, J. R., Garotta, G., Silvennoinen, O., Ihle, J. N. \& Pestka, S. (1995). J. Biol. Chem. 270, 20915-20921.

Krause, C. D., Lavnikova, N., Xie, J., Mei, E., Mirochnitchenko, O. V., Jia, Y., Hochstrasser, R. M. \& Pestka, S. (2006). Cell Res. 16, 55-69.

Landar, A., Curry, B., Parker, M. H., DiGiacomo, R., Indelicato, S. R., Nagabhushan, T. L., Rizzi, G. \& Walter, M. R. (2000). J. Mol. Biol. 299, 169-179.

Langer, G., Cohen, S. X., Lamzin, V. S. \& Perrakis, A. (2008). Nature Protoc. 3, 1171-1179.

Langer, J. A., Cutrone, E. C. \& Kotenko, S. (2004). Cytokine Growth Factor Rev. 15, 33-48.
Larsen, K. S., Østergaard, H., Bjelke, J. R., Olsen, O. H., Rasmussen, H. B., Christensen, L., Kragelund, B. B. \& Stennicke, H. R. (2007). Biochem. J. 405, 429-438.

Lin, F.-C. \& Young, H. A. (2013). Adv. Biosci. Biotechnol. 04, 6-13.

Logsdon, N. J., Deshpande, A., Harris, B. D., Rajashankar, K. R. \& Walter, M. R. (2012). Proc. Natl Acad. Sci. USA, 109, 1270412709.

Long, F., Vagin, A. A., Young, P. \& Murshudov, G. N. (2008). Acta Cryst. D64, 125-132.

Marsters, S. A., Pennica, D., Bach, E., Schreiber, R. D. \& Ashkenazi, A. (1995). Proc. Natl Acad. Sci. USA, 92, 5401-5405.

McElroy, C. A., Dohm, J. A. \& Walsh, S. T. R. (2009). Structure, 17, $54-65$.

Miknis, Z., Margracheva, E., Li, W., Zdanov, A., Kotenko, S. W. \& Wlodawer, A. (2010). J. Mol. Biol. 404, 650-664.

Mikulecký, P., Černý, J., Biedermannová, L., Petroková, H., Kuchař, M., Vondrášek, J., Malý, P., Šebo, P. \& Schneider, B. (2013). Biomed Res. Int. 2013, 752514.

Moncada-Vélez, M. et al. (2013). Blood, 122, 2390-2401.

Moura, P. R. de, Watanabe, L., Bleicher, L., Colau, D., Dumoutier, L., Lemaire, M. M., Renauld, J.-C. \& Polikarpov, I. (2009). FEBS Lett. 583, 1072-1077.

Murshudov, G. N., Skubák, P., Lebedev, A. A., Pannu, N. S., Steiner, R. A., Nicholls, R. A., Winn, M. D., Long, F. \& Vagin, A. A. (2011). Acta Cryst. D67, 355-367.

O'Boyle, N. M., Banck, M., James, C. A., Morley, C., Vandermeersch, T. \& Hutchison, G. R. (2011). J. Cheminform. 3, 33.

Okonechnikov, K., Golosova, O. \& Fursov, M. (2012). Bioinformatics, 28, 1166-1167.

Pestka, S., Kotenko, S. V., Muthukumaran, G., Izotova, L. S., Cook, J. R. \& Garotta, G. (1997). Cytokine Growth Factor Rev. 8, 189206.

Pettersen, E. F., Goddard, T. D., Huang, C. C., Couch, G. S., Greenblatt, D. M., Meng, E. C. \& Ferrin, T. E. (2004). J. Comput. Chem. 25, 1605-1612.

Plíhal, O., Sklenář, J., Kmoníčková, J., Man, P., Pompach, P., Havlíček, V., Křen, V. \& Bezouška, K. (2004). Biochem. Soc. Trans. 32, 764-765.

Pompach, P., Man, P., Kavan, D., Hofbauerová, K., Kumar, V., Bezouška, K., Havlíček, V. \& Novák, P. (2009). J. Mass Spectrom. 44, 1571-1578.

Ring, A. M., Lin, J.-X., Feng, D., Mitra, S., Rickert, M., Bowman, G. R., Pande, V. S., Li, P., Moraga, I., Spolski, R., Özkan, E., Leonard, W. J. \& Garcia, K. C. (2012). Nature Immunol. 13, 11871195.

Rüger, R., van Lenthe, E., Lu, Y., Frenzel, J., Heine, T. \& Visscher, L. (2015). J. Chem. Theory Comput. 11, 157-167.

Savan, R., Ravichandran, S., Collins, J. R., Sakai, M. \& Young, H. A. (2009). Cytokine Growth Factor Rev. 20, 115-124.

Schilling, B., Row, R. H., Gibson, B. W., Guo, X. \& Young, M. M. (2003). J. Am. Soc. Mass Spectrom. 14, 834-850.

Schoenborn, J. R. \& Wilson, C. B. (2007). Adv. Immunol. 96, 41-101.

Sievers, F., Wilm, A., Dineen, D., Gibson, T. J., Karplus, K., Li, W., Lopez, R., McWilliam, H., Remmert, M., Söding, J., Thompson, J. D. \& Higgins, D. G. (2011). Mol. Syst. Biol. 7, 539.

Thiel, D. J., le Du, M.-H., Walter, R. L., D'Arcy, A., Chène, C., Fountoulakis, M., Garotta, G., Winkler, F. K. \& Ealick, S. E. (2000). Structure, 8, 927-936.

Thomas, C., Moraga, I., Levin, D., Krutzik, P. O., Podoplelova, Y., Trejo, A., Lee, C., Yarden, G., Vleck, S. E., Glenn, J. S., Nolan, G. P., Piehler, J., Schreiber, G. \& Garcia, K. C. (2011). Cell, 146, 621-632.

Walter, M. R., Windsor, W. T., Nagabhushan, T. L., Lundell, D. J., Lunn, C. A., Zauodny, P. J. \& Narula, S. K. (1995). Nature (London), 376, 230-235.

Yoon, S.-I., Jones, B. C., Logsdon, N. J., Harris, B. D., Deshpande, A., Radaeva, S., Halloran, B. A., Gao, B. \& Walter, M. R. (2010). Structure, 18, 638-648. 